\title{
An Intelligent Decision Support System for Faculty Evaluation
}

\author{
Hegazy Zaher \\ Institute of Statistical \\ Studies and Research \\ (ISSR), Cairo University, \\ Egypt.
}

\author{
W. F. Abd El- \\ Wahed \\ Faculty of computers \& \\ Information, Shiben El- \\ Kom, Menoufia University, \\ Egypt.
}

\author{
Mahmoud M. El- \\ Sherbiny, \\ Operations Research \\ Dept, Institute of Statistical \\ Studies and Research (ISSR), \\ Cairo University, Egypt. \\ m_sherbiny@yahoo.com
}

\author{
Haidy M.E. Matloub \\ Enrolled for MSc. Degree \\ in Operations Research, \\ (ISSR), Cairo University, \\ Egypt
}

\begin{abstract}
This paper presents an intelligent decision support system (IDSSFPE) for faculty performance evaluation. The requirements of the faculty decision makers are identified through the analysis and the design of the IDSSFPE. Three models based of the IDSSFPE are illustrated. Such models are: i) The performance measurement model based on data envelopment analysis (DEA), ii) Number of applicants estimation model, and iii) Applicants classification model based on artificial neural network (ANN).
\end{abstract}

Keywords: Faculty performance, Intelligence decision support system, Artificial neural network

\section{Introduction}

Over last decade, new technologies like artificial neural networks (ANN) have seen a rapid acceptance for solving a wide range of business problems. Many papers have been reviewed ANN from various points of view. Simth and Gupta [28] review ANN applications and techniques for the operations researcher. Bel Raggad used ANN as a technology for knowledge resources management [3] and Bijayananda using it in the field of education to predict MBA students' success [4].

Also, Data envelopment analysis (DEA) is a methodology that has been used to evaluate the efficiency of entities. DEA used in various fields based on [14] such as, Jill Johnes measure teaching efficiency in higher education to graduates from UK universities [20]. J.Colin et al using computed DEA based efficiency scores for policy evaluations and possible funding guidance in UK higher education [18]. Jill Johnes explores the advantages and drawbacks of various methods for measuring efficiency in higher education context [19]. B.Casu and E.Thannssaulis evaluate cost efficiency in UK university control administration [2]. Colbert used DEA to determine the relative efficiency of 24 top ranked US MBA programs [7].

White in [31] points out that the trend of decision support system (DSS) will come into increased use in universities, as their administrators management scientists combine their managerial skills with quantitative techniques for organizing and presenting information. Elsa et al in [12] discusses a balanced scorecard approach for strategy and quality driven universities. Roger and Saud [27] develop a DSS to enable systematic exploration of educational database.

In literature the usage of DEA in a DSS is not a large scale. Such as, W.K. Wang describes knowledge-base DSS for measuring the performance of government real state investment using DEA models [33]. Marta et al used it as a tool for integrating heterogeneous data model applies fuzzy logic to decision support systems [21].

Some applications combined DEA and ANN models, such as, Parag and James in [25] used this combination to improve forecasting accuracy of neural networks under monotonicity assumption. Desheng, Zijiang and liang in [10] integrate DEA and ANN to examine the relative branch efficiency of a big Canadian bank. Parag in [26] used DEA to illustrate that nonlinear variable return to scale (VRS) with empirical data and compare the performance of non-linear ANN with linear regression model. 
This paper, combine the DSS, ANN and DEA for building an Intelligent Decision Support System for Faculty Performance Evaluation (IDSSFPE) and applying such system on El-Menoufia University. Such IDSSFPE integrates number of applicants admitted, evaluation performance for a faculty, and classify applicants to each department in a faculty. The number of applicants admitted to a faculty and to each department is estimated using ANN while Evaluation performance for a faculty is analyzed by applying DEA. The remaining parts of this paper are arranged as

follows: Section 2 contains problem description. Section 3 the architecture of IDSSFPE is discussed. In section 4

discuses a case study applied IDSSFPE. Section 5 contains the analysis of results. Finally the conclusion is summarized in section 6.

\section{Problem Description}

Based on the way to ensure quality for higher education in Egypt, the IDSSFPE was build to help top management to take decisions concerning to the needs for measuring the performance of faculties, determine number of applicants admitted to any faculty, and applicants admitted to each department in a faculty.

Menoufia University is one of the higher education institutions in Egypt. Therefore, it is considered to the natural outlet for secondary school graduates seeking for university education form its location and other locations in Egypt. They wants to join the university based on his/her grades or as a best location university. Therefore, the IDSSFPE was used in order to evaluate the performance of faculties in Menoufia University.

\section{The IDSSFPE Architecture}

The Architecture of IDSSFPE developed for the use of faculty decision-making as outlined in Fig 1 which consists of the following parts:

- User Interface,

- Database, and

- $\quad$ Model -Base Module.

The main components and functions of each part will be illustrated in the following sections.

3.1. The User Interface The user interface of IDSSFPE for a faculty performance evaluation is a menu driven and user-friendly interface. It allows the DM to interact with other modules of the IDSSFPE. It has a capability to enter/open database implemented by FPE program. It permits a DEA and EMS software to be run as independent software. The UI includes a set of links to the IDSSFPE modules and accesses the DB and facilitates accessing to run the DEA modules, creating the classification and forecasting databases in addition to trains ANN to specify number of applicants admitted to a faculty and specify which applicants enter each department in a faculty.

3.2. The Database The database module divided into two parts. External database that can be generated out of program FPE to use in Frontier Analyst Software to measure performance, while internal database makes by program FPE and used for forecasting or classification in a faculty.

3.3. Model-Base Modules The model-base module incorporates multiple functionalities or tools into a loosely couple single package in such a way that they can be used independently. The major issues during the development of the IDSSFPE were the selection of model types and computing technology. The models developed to be included in the IDSSFPE are:

i. Forecasting Model

ii. Classification Model

iii. Performance assessment Model

The main components and the role of each model in the IDSSFPE will be illustrated in the following section. 


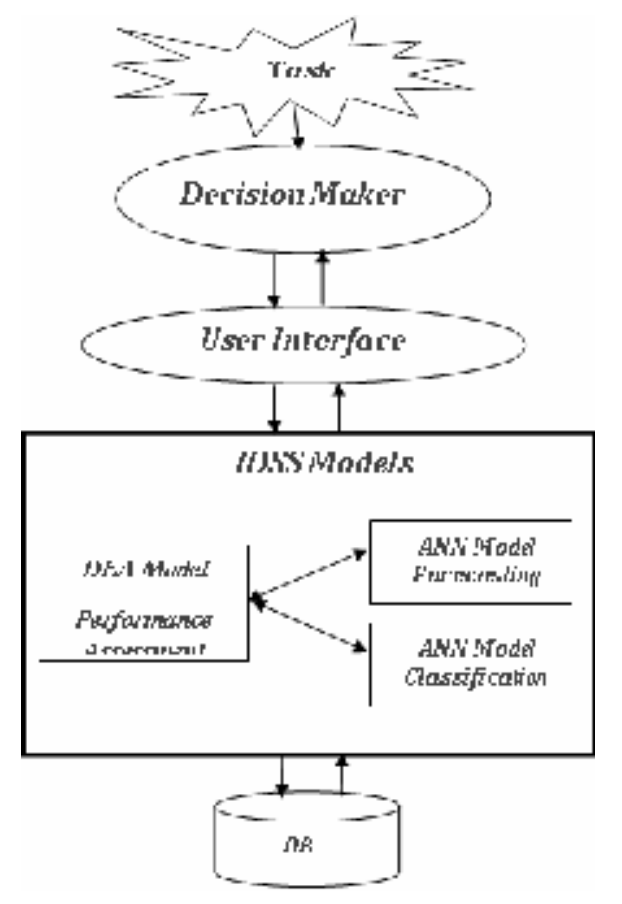

Figure 1. The Main Components Of The IDSSFPE

\section{i. Forecasting Model}

Forecasting models naturally highlight variable that have significant variation over the forecasting periods and can be forecasted well. In higher education two methodologies are used in enrollment forecasting. The first is econometric model and the second is trend model. Econometric forecasting Models used for identifying the determinants of enrollment rates rather than forecasting the enrollment Trend Models while the methodology of trend model is straightforward [9]. These models can be based on predicting the path of the college enrollment rate or total enrollment. The models can be statistical trend fitting models or can be based on "expert" judgment as to future rate of change the forecast performance of the various trend models should be analyzed [1].

In recent years ANN is identified as model for forecasting. Many studies have shown that neural networks can be one of the very useful tools in forecasting. Neural networks have flexible nonlinear function mapping capability that can approximate any continuous function with arbitrarily desired accuracy [8,17]. ANN are also nonparametric data-driven models that impose little prior assumptions on the underlying processes from which data are generated. As such, ANN are less susceptible to the model misspecification problem than most parametric nonlinear methods [15]. Neural networks are trainable analytic tool that attempt to mimic information processing patterns in the brain [16]. Because of ANN do not necessarily require assumptions about population distribution, economists, mathematicians and statisticians are increasingly using it for data analysis [15]. ANN not only doesn't require assumption about underlying population but also it is a powerful forecasting tool that draws on the most recent development in artificial intelligence research. With the advent of modern computer technology and information science sophisticated information systems can built that make decisions or predictions based on information contained in available past data. Such systems are called learning systems and are currently used for the purpose of classification or predictions [32]. Tsoukalas and Uhrig [29] define a neural network as a data processing system consisting of a large number of simple highly interconnected processing elements (artificial neurons) in architecture by the structure of cerebral cortex of the brain. Approximately $95 \%$ of the reported neural network business applications used the multiplayer feed forward neural networks (MFNN) with the back propagation-learning rule [34]. This type of neural network is popular [28] because its abroad applicability to many problem domains of relevance to business: principally predictions, classification, and modeling. MFNN is appropriate for solving problems that involve learning the relationships between a set of inputs and known outputs. Based on the above-mentioned models' review used in forecasting, 
the MFNN is selected in this paper to sole number of applicants' estimation. MFNN is a collection of interconnected homogenous processing unit, called neuron. A neuron activity is controlled by a continuous and differentiable mathematical function that aggregates input signals received from other neurons and produce output signals transmitted to other neurons. The flow of information is from left to right, with the input layer receives input data describing the decision domain passed through the network via the hidden layer of neurons. The number of nodes constituting the hidden layer depends on the complexity of pattern in input data. Then to the output layer, which is prepares the response representing the situation outcome. Fig 3 shows the general architecture of a MFNN used in the IDSSFPE. The output for algorithm of ANN known because the decision maker don't determine number of applicants admitted to faculty based on faculty needs only but this number specified from the high council of universities. Therefore, a neural network with back propagation learning rule approach is used for this situation. Based in input variable in decision domain a recommended number of applicants admitted to faculty would be obtained.

Many steps are followed in building a forecasting model using neural network as state in [30]. The development process for ANN application includes nine steps as shown in Fig.3. In the next sections some of these steps of flow diagram examined in more detail:

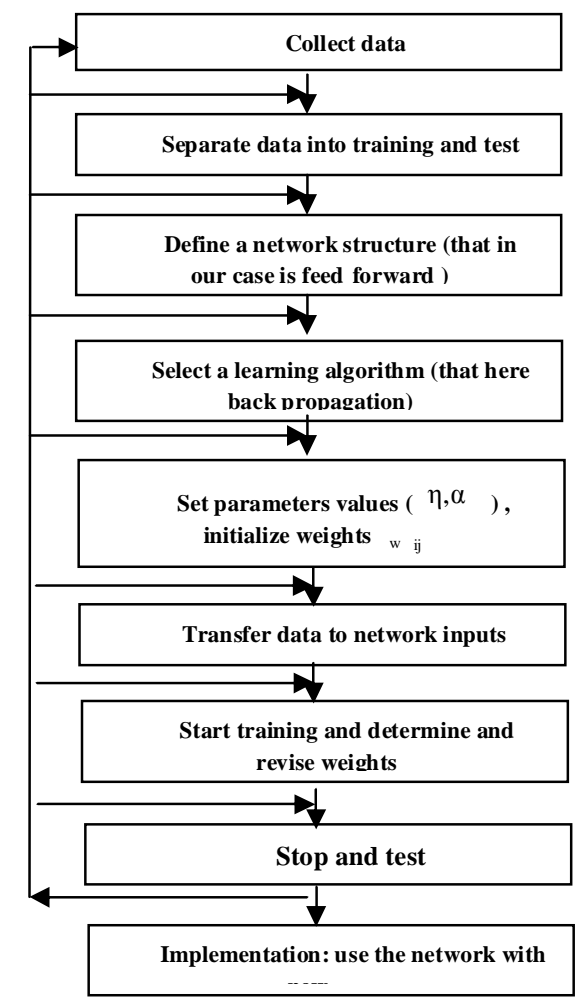

Figure 2. Flow diagram of the development process of an ANN

\section{Collect Data}

The data used in the IDSSFPE are collected from Menoufia University of the academic year 2002/2003. The data considered to be the inputs of the forecasting model are: the number of professors which is considered as an approximation of resources available for faculty teaching, the faculty supported from scientific search unity which is considered as sound indicator for the performance of a faculty and its research, and the cost of social solidarity which is considered as an approximation for expenses on applicant as aid.

While the output of that model are the number of enrollment applicants in a faculty which considered to be as an indicator for quality of student on admission. 


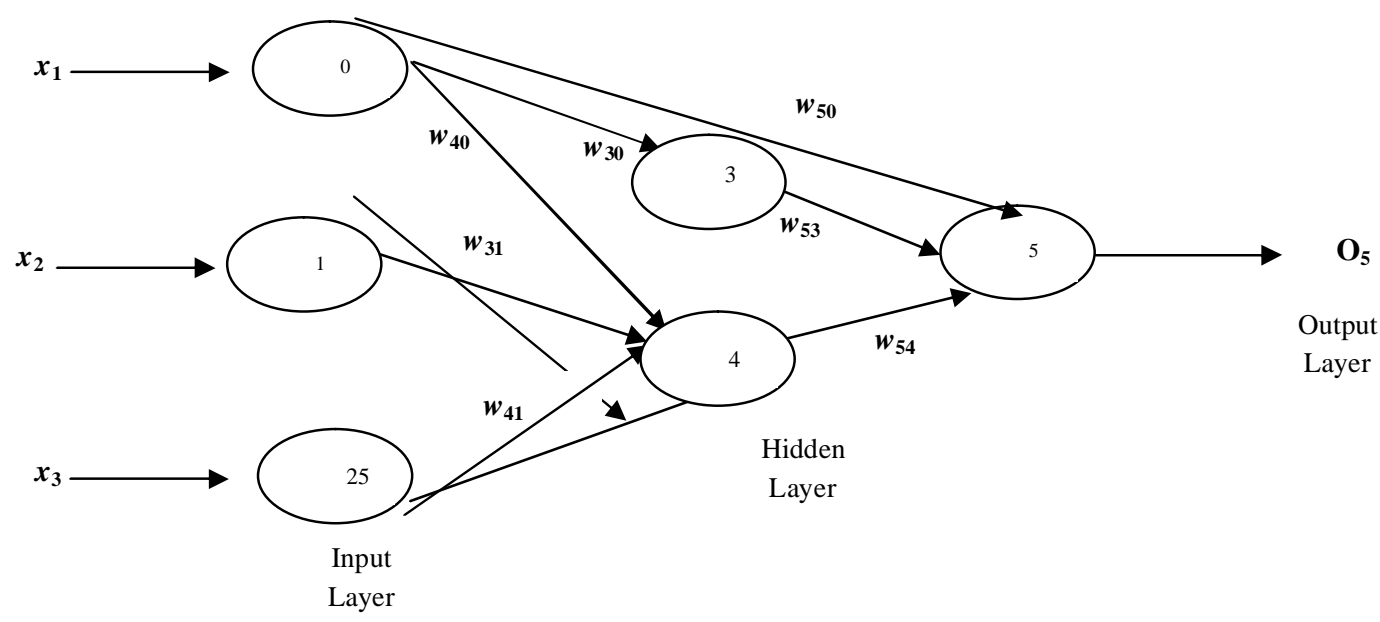

Network Structure

One of the most critical decisions is the network architecture. That means the number of layers, the number of nodes in each layer, and how nodes are connected. In our situation a multiplayer feed forward neural network (MFFN) is chosen and then input nodes, output nodes, number of hidden layer, number of hidden nodes are determined. In network used by program chosen to be with three layer, input layer contains nodes based on the attributes of data set that user enter, number of hidden nodes increase by one of input node, and finally the output layer contains one node that represents the forecasted number of applicants to faculty.

\section{Transfer data to network}

The decisions made in this phase of development are critical to the performance of a network. The goal of data preparation is to reduce nonlinearity when its character is known and let the network resolve the hidden nonlinearities that not are understood.

\section{Scaling data}

While loading data from the database file, minimum value and maximum value for each column are determined. The values of inputs between minimum and maximum (called range $\Delta$ ) must be scaled into the range 0.1 to 0.9 for the neural network input.

The equation for scale input is [29]:

$$
y=(0.8 / \Delta) x+\left[0.9-\left(0.8 x_{\text {max }} / \Delta\right)\right]
$$

Where:

$y$ is the value of data scaled,

$\Delta$ is the range between maximum and minimum value $\left(\Delta=x_{\max }-x_{\min }\right)$, and

$x$ is the value of input will be transfer or scale.

Scaling variable between 0.1 and 0.9 is often used to limit the amount of sigmoid activation function used in the representation of variables in order to avoid "network paralysis". When the network is run, the output produced must be scaled. 


\section{Network training}

Training the ANN is an iterative process that starts from random set of weights and gradually enhances the fitness of the network model and the known data set. The iteration continues until the error sum is converged to low acceptable level. In the back propagation algorithm, two parameter learning rate and moment adjusted to control the speed of reaching the minimum ratio of the different between calculated value and value of training cases. Taking these steps, the following parameters have been used for the MFNN design:

$\begin{array}{ll}\text { Threshold } & 0.1 \text { or less } \\ \text { Learning rate }(\eta) & 0.6 \\ \text { Moment }(\alpha) & 0.9 \\ \text { Error, }(E) & 0.01\end{array}$

Uses $\eta^{*}=\frac{\eta}{1-\alpha}=\frac{0.6}{1-0.9}=0.25$ for as better learning rate and iterations 100000 .

\section{ii. Classification Model}

The data collected from faculty of computers \& information to be considered as the inputs of classification model are the grades of students in the following courses: Logic design (LD), Data Structure (DS), Operations Research (OR), Computer Software (CS). The output of the model is the applicants' classification to department that represents the admission policy to each department. The MFNN with back propagation learning rule is used to build this model for classifying applicants to each department in a faculty. The same nine steps used in forecasting model are followed in building the classification model.

\section{iii. Performance assessment model:}

Model for performance assessment was selected on the basis of the required output, which means measure the efficiency of a faculty based on its inputs and outputs.

Data Envelopment Analysis (DEA) initiated by Charnes, Cooper and Rhodes [5] is a linear programming-based technique for measuring the performance of administrative units. The performance of a unit is evaluated by comparing its performance with the best performing units of the sample. The measure of performance is expressed in the form of efficiency score. DEA is a non-parametric linear programming technique for measuring the relative efficiency of decisionmaking units (DMUs) that perform the same type of functions and have the identical goals and objectives. The notion of efficiency employed in the DEA approach is termed Pareto Efficiency, which is an extension of the social choice criterion of Pareto Optimality [23]. An advantage of DEA is that there is no preconceived functional form imposed on the data in determining the efficient units. That is, DEA estimates the production function of efficient DMUs using piecewise linear programming on the sample data instead of making restrictive assumptions about the underlying production technology. As an efficient frontier technique, DEA identifies the inefficiency in a particular DMU by comparing it to similar DMUs regarded as efficient. The efficiency of each DMU is measured relative to all other DMUs under the restriction that all DMUs lay on or below the efficient frontier. The DMUs indicated as efficient are only efficient in relation to others in the sample. The principal disadvantage of DEA is that it assumes data to be free of measurement error. While the need for reliable data is the same for all statistical analysis, DEA is particularly sensitive to unreliable data because the units deemed efficient determine the efficient frontier and, thus, the efficiency scores of those units under this frontier [24]. DEA appears as the most appropriate methodology for higher education evaluations.

DEA maximize the ratio of a weighted sum of outputs to a weighted sum of inputs where the attached weights to inputs and outputs are treated as variables that are to be optimized. The estimation procedure of the relative efficiency score for each DMU can be described as follows. Firstly, the best practice production function is generated by a set of DMU that 
receive the maximum output amounts for a given level of inputs compared with the other DMUs, called relatively efficient. Secondly, for each department DEA produces an efficiency score by comparing the other non-efficient DMUs with the production frontier. These DMUs not lying on the frontier are called inefficient. Whereas the efficiency score for the frontier generating DMUs equals one, the distance to the efficiency frontier determines the level of inefficiency. Assume there is $n$ DMUs that are denoted by index $j$. Each DMU uses $m$ inputs to produce $p$ outputs. DMU $j$ uses the amount $x_{i j}$ of input $i$ to produce the amount $y_{k j}$ of output $k$. The assigned weight to output $k$ is $u_{k}$ and the weight assigned to input $i$ is $v_{i}$. Productivity is defined as the ratio of the weighted sum of outputs to the weighted sum of inputs. Thus, the relative efficiency of a DMU can be written as (2).

$$
E_{o}=\frac{\sum_{k=1}^{p} u_{k} y_{k o}}{\sum_{i=1}^{m} v_{i} x_{i o}}
$$

By determining the weights of the inputs and outputs endogenously, DEA permits a DMU to adopt a set of weights that will maximize its productivity ratio without exceeding 1 for other DMUs. Introducing this constraint converts the productivity ratio into a measure of relative efficiency as in (3).

The constraints mean that the ratio of virtual output to virtual input of the other DMUs does not exceed 1 for every DMU. Assuming that the DMUo is evaluated, the objective is to obtain weights $\mathrm{u}$ and $\mathrm{v}$ in such a way that the ratio of DMUo is maximized. Furthermore the non-negative constraint must hold for the weights.

$$
\begin{aligned}
& \underset{u_{k}, v_{i}}{\operatorname{maximize}} \mathrm{E}_{\mathrm{o}}=\frac{\sum_{\mathrm{k}=1}^{\mathrm{p}} u_{k} y_{k o}}{\sum_{\mathrm{i}=1}^{\mathrm{m}} v_{\mathrm{i}} x_{i o}} \\
& \text { subject to : } \\
& \frac{\sum_{\mathrm{k}=1}^{\mathrm{p}} u_{k} y_{k j}}{\sum_{\mathrm{i}=1}^{\mathrm{m}} v_{\mathrm{i}} x_{i j}} \leq 1 \quad ; \mathrm{j}=1, \ldots \ldots ., \mathrm{n}, \\
& \frac{u_{k}}{\sum_{\mathrm{i}=1}^{\mathrm{m}} v_{\mathrm{i}} x_{i j}}>\varepsilon ; k=1, \ldots ., p \\
& \frac{v_{\mathrm{i}}}{\sum_{\mathrm{i}=1}^{\mathrm{m}} v_{\mathrm{i}} x_{i j}}>\varepsilon ; i=1, \ldots . ., m .
\end{aligned}
$$

The mathematical formulation of DEA is represented in (4) [22]. 


$$
\begin{aligned}
& \max E_{o}=\frac{\sum_{j=1}^{J} u_{j}{ }^{y}{ }_{j m}}{\sum_{i=1}^{I} v_{i}{ }^{x}{ }_{i m}} \\
& \text { s.t. } \\
& \sum_{j=1}^{J} u_{j}{ }^{y}{ }_{j n} \\
& \sum_{i=1}^{I} v_{i} x_{i n} \\
& u_{j} \geq 0 \quad, v_{i} \geq 0 \\
& \text { where }\left[\begin{array}{l}
j=1, \ldots . ., J \\
i=1, \ldots \ldots, I
\end{array}\right]
\end{aligned}
$$

where:

$E_{o}$ is the efficiency of unit $o$.

$y_{j n}$ is the observed quantity of output $\mathrm{j}$ produced by unit $n=1,2, \ldots \ldots ., N$

$x_{i n}$ is the observed quantity of input i produced by unit $n=1,2, \ldots \ldots ., N$

$u_{j}$ is the weight (to be determined) given to output $j$ by base unit $o$

$v_{i}$ is the weight (to be determined) given to input $i$ by base unit $o$

Remark: A fully rigorous development would replace $u_{j}, v_{i} \geq 0$ with $\frac{u_{k}}{\sum_{\mathrm{i}=1}^{\mathrm{m}} v_{\mathrm{i}} x_{i j}}, \frac{v_{\mathrm{i}}}{\sum_{\mathrm{i}=1}^{\mathrm{m}} v_{\mathrm{i}} x_{i j}}>\varepsilon \geq 0$ where $\varepsilon$ is a non-

Archimedean elemant smaller than any positive real number.

The linear program solution technique will attempt to make efficiency of the unit as large as possible. The search procedure will terminate when some of the efficiencies hit 1.

The data considered to be the inputs of performance assessment model are collected from the university performance report. These data are :-

\section{Inputs:}

- Enrollment student: Number of applicants enrolled in a faculty for $1^{\text {st }}$ year

- Students/teacher ratio: is the ratio between enrolled applicants and their teachers, is a sound indicator of level resources and effective level supervision in teaching programs.

- Master Registrations: Number of postgraduate applicant enrolled in Master degree in year $n$.

- PhD Registration: Number of postgraduate applicants enrolled in $\mathrm{PhD}$ degree in year $n$.

\section{Outputs:}

- Graduation number: Number of undergraduate applicant graduate in year $n$.

- Master graduates: Number of postgraduate applicant obtains the Master degree in year $n$.

- $\mathrm{PhD}$ graduates: Number of postgraduate applicant obtain the $\mathrm{PhD}$ degree in year $n$

- Number of conferences: Number of conferences proceeded by faculty in national \& international domain. 


\section{Case Study}

In this paper, the IDSSFPE with DEA and ANN technique applied to a case study in Menoufia University to assessment performance of 11 faculties in university, forecast enrollment applicant to them, and classify applicants to departments in faculty of computers \& information.

\section{Forecasting Model}

In the case study the neural network using this model are Consist of three layers; which are input layer, one hidden layer and output layer (total three layers) was used.

- The input layer has three inputs which are Faculty Supported from scientific search unity (FSSSU), Social Solidarity (SS), and number of Professors (\#of Prof) in the faculty.

- The output layer has only one neuron and one output, namely forecasting (number of applicant admitted).

The neural network model was built using FPE software developed by c\#. The model was trained with 11 data points represented.

\section{Classification Model}

Faculty of computers \& information used as a sample of faculties to classify student to each department. Neural network for this model with three layers was used, input layer has four inputs, which are grades of students in the following courses: logic design (LD), Data Structure (DS), Operations Research (OR), and Computer Science (CS). The output layer has only one neuron and one output, namely classification.

\section{Performance assessment Model}

In the IDSSFPE, DEA is conducted for measure performance of a faculty in Menoufia University. For faculty performance, the analysis is performing using the inputs and outputs mentioned in 3.3 (iii).

Selecting analysis options in DEA

The analysis options available in DEA are: Input minimization (also known as input orientation or contraction) instructs DEA to reduce the inputs as much as possible without dropping the output levels. Alternatively, when management's focus is on raising productivity without increasing the resource base, output maximization (also known as output orientation or expansion) could be specified. under output maximization, outputs are raised without increasing the inputs. It is worth noting that when none of the inputs is controllable by management (not the case in this study), one can only specify the output maximization model. The current study contributes to the DEA modeling investigations of MU faculties by computing an efficiency measures by making allowance for input measurement minimization and output maximization for radial adjustments. This model computed also assumes a convex technology. Another analysis option in DEA is a choice between constant returns to scale (CRS) and variable returns to scale (VRS). when computing the technical efficiency (TE) measures. Clearly the CRS assumption is only appropriate when all faculties are operating at an optimal scale. If this is not the case, the TE measures will be confounded by scale efficiencies. Consequently, in the latter case, the VRS assumption should be employed so as to compute TE measures that are devoid of these scale efficiency effects [6]. The VRS model will always envelop the data more closely than the CRS model, irrespective of whether variable returns to scale exist [11]. The appropriate returns to scale assumption is employed with respect to the data utilized in the current study, is a CRS assumption.

Sample to Faculty of Engineering (Sheben): 
The mathematical model:

$$
\begin{aligned}
& \operatorname{Max} \mathrm{E}_{F o A}=\frac{571 u_{1}+20 u_{2}+4 u_{3}+32 u_{4}+9 u_{5}}{4732 v_{1}+23 v_{2}+70 v_{3}+10 v_{4}} \\
& \text { s.t. } \\
& \mathrm{E}_{\mathrm{FoA}} \leq 1 \\
& \mathrm{E}_{\mathrm{FoEn}} \leq 1 \\
& . . \\
& . \\
& . \\
& \mathrm{E}_{\mathrm{C} \& \mathrm{I}} \leq 1 \quad u_{j} \geq 0 \mathrm{j}=1, \ldots, 5 \\
&
\end{aligned}
$$

Transformation to LP for faculty of Engineering based on equation (4):

$$
\max _{\mathrm{u}, \mathrm{v}} z=517 u_{1}+20 u_{2}+4 u_{3}+32 u_{4}+9 u_{5}
$$

subject to :

$$
\begin{gathered}
517 u_{1}+20 u_{2}+4 u_{3}+32 u_{4}+9 u_{5}-4732 v_{1}-23 v_{2}-70 v_{3}-10 v_{4} \leq 0 \\
211 u_{1}+23 u_{2}+24 u_{3}+13 u_{4}+6 u_{5}-873 v_{1}-6 v_{2}-27 v_{3}-24 v_{4} \leq 0 \\
1953 u_{1}+12 u_{2}+6 u_{3}+15 u_{4}-9394 v_{1}-208 v_{2}-22 v_{3}-10 v_{4} \leq 0 \\
421 u_{1}+29 u_{2}+8 u_{3}+30 u_{4}+3 u_{5}-2361 v_{1}-15 v_{2}-65 v_{3}-9 v_{4} \leq 0 \\
780 u_{1}+u_{2}+4 u_{3}+9 u_{4}+6 u_{5}-10335 v_{1}-272 v_{2}-70 v_{3}-10 v_{4} \leq 0 \\
314 u_{1}+72 u_{2}+45 u_{3}+13 u_{4}+22 u_{5}-2204 v_{1}-7 v_{2}-120 v_{3}-65 v_{4} \leq 0 \\
1005 u_{1}+4 u_{3}+8 u_{4}+4 u_{5}-15140 v_{1}-330 v_{2}-8 v_{4} \leq 0 \\
1404 u_{1}+36 u_{2}+4 u_{3}+8 u_{4}+2 u_{5}-9114 v_{1}-82 v_{2}-228 v_{3}-4 v_{4} \leq 0 \\
518 u_{1}+33 u_{2}+10 u_{3}+11 u_{4}+2 u_{5}-1605 v_{1}-39 v_{2}-61 v_{3}-27 v_{4} \leq 0 \\
517 u_{1}+20 u_{2}+4 u_{3}+5 u_{4}-1107 v_{1}-158 v_{2}-70 v_{3}-10 v_{4} \leq 0 \\
644 u_{1}+2 u_{4}-315 v_{1}-23 v_{2} \leq 0 \quad v_{1} \\
4732 v_{1}+23 v_{2}+70 v_{3}+10 v_{4}=1 \\
u_{j} \geq 0 \mathrm{j}=1, \ldots, 4 \\
v_{i} \geq 0 \mathrm{i}=1, \ldots .4
\end{gathered}
$$

There are mathematical formulations for each faculty of 11 faculties in Menoufia University, which are (agriculture, engineering, education, science, commerce, medicine, law, arts, home affairs, tourism \& hotels, computers \& information)

\section{Analysis of Results}

5.1. Result of Forecasting Model: As mentioned before that the MFNN model used to solve the forecasting model, which used for predict the number of applicant admitted to a faculty. The result is shown in Fig 4. The column called output is a recommendation for the decision maker, assist him to make decisions based on this recommendations. 


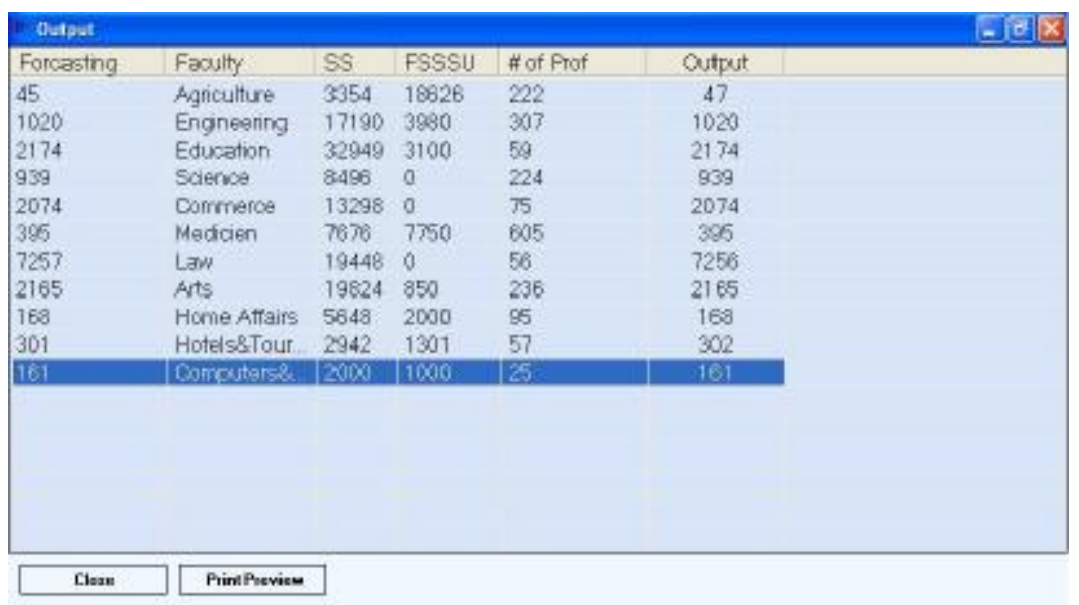

Figure 4 Result of Forecasting Model

This recommendation may be different if the decision maker change of the setting of network such as number of iteration or learning rule or the both. The difference in recommendation based also on the change of decision domain meaning, the input variable to neural network.

In our case of faculties of Menoufia University the result with error 0.02 at learning rate 0.3 and 400 iterations. Then the DM uses these recommendations as an input for performance assessment model to notice the effect of number of applicants admitted to his faculty performance.

5.2. Result of Classification Model: The classification model used to classify applicant to each department in a faculty. The results show in Fig 5. The output columan is a recommendation for preferred department for this applicant. the decision maker make decisions based this recommendation. This recommendation may be different if the decision maker changes the setting of network such as number of iterations or learning rate or both.

The difference in recommendation based also on the change of decision domain meaning, the change in input variables to neural network.

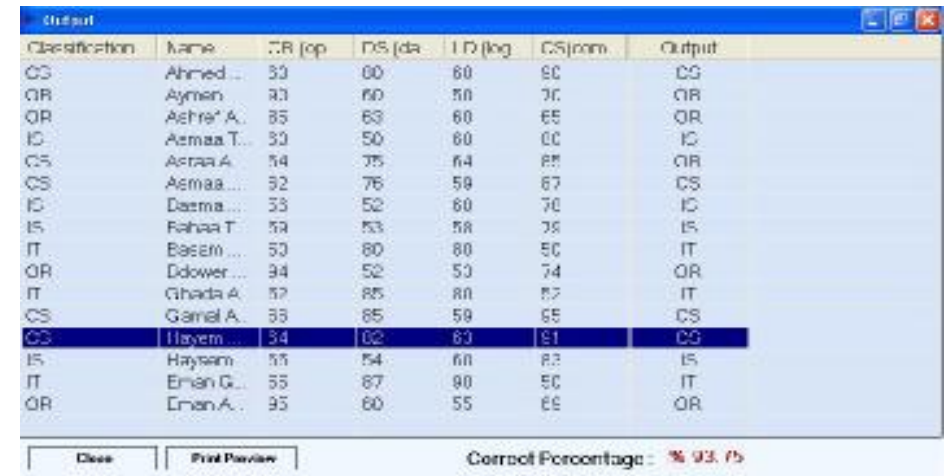

Figure 5 Result of Classification Model in Faculty of Computers \& Information

In our case faculty of computers \& information the classification ability of MFNN model was 93.75 at learning rate 0.25 and 500 iterations.

5.3. Result of Performance assessment Model: The performance assessment model that use a DEA based input and output variables specify up performance indicators of quality assurance in higher education [13].

Program IDSSFPE uses software Frontier Analyst to solve performance assessment model. Each software can be used independently, the software results are the following. 
Table 1 Exhibit the performance score of each faculty based inputs and outputs mention in section 3.3 (iii). The two options classified the Faculty of Agriculture, Faculty of Engineering (Shbeen), Faculty of Science, Faculty of Medicine, Faculty of Arts, Faculty of Tourism \& Hotels, and Faculty of Computers \& Information as an efficient faculties where each faculty has $100 \%$ performance, while Faculty of Education, Faculty of Commerce, Faculty of Law, and Faculty of Home Affairs are classified as inefficient faculties where each faculty has less than $100 \%$ performance.

In order to improve the performance of inefficient faculties, some inputs may decrease and some output may increase. Table 2 exhibits the Potential Improvement of two options used concerning each inefficient faculty. The variable with sign $(-)$ is an input variable that may be decrease with this percent to the target level, while variables with sign (+) is an output variables that may be increase with this percent from the target level.

The efficiency results suggest that the Menoufia faculties are operating at a fairly high level of efficiency relative to each other, although there is a chance for improvement in several faculties. The way to improve each faculty are illustrative in Table 2.based on these result of performance assesment model the decision maker can change of decision domain of applicants' classification that effect on graduation number and also in faculty performance.

Table 1. Faculty Performance

\begin{tabular}{|c|c|c|}
\hline Faculties & CCR Input-Min & CCR Output-Max \\
\hline Faculty of Agriculture & $100 \%$ & $100 \%$ \\
\hline Faculty of Engineering(shpeen) & $100 \%$ & $100 \%$ \\
\hline Faculty of Education & $88.39 \%$ & $88.39 \%$ \\
\hline Faculty of Science & $100 \%$ & $100 \%$ \\
\hline Faculty of Commerce & $43.42 \%$ & $43.42 \%$ \\
\hline Faculty of Medicine & $100 \%$ & $100 \%$ \\
\hline Faculty of Law & $64.19 \%$ & $64.19 \%$ \\
\hline Faculty of Arts & $100 \%$ & $100 \%$ \\
\hline Faculty of Home Affairs & $95.48 \%$ & $95.48 \%$ \\
\hline $\begin{array}{c}\text { Faculty of Tourism \& Hotels } \\
\text { Faculty of Computers \& } \\
\text { Information }\end{array}$ & $100 \%$ & $100 \%$ \\
\hline
\end{tabular}

\section{Conclusion}

This paper has outlined the features of an IDSSFPE technique to evaluate performance of a faculty based on DEA and ANN techniques. The DEA is used as an efficiency tool to measure performance of a faculty while the ANN is used as an evaluation tool to forecast number of applicants admitted to the faculty and also, to classify applicants into departments of the faculty. Such IDSSFPE can be considered as a valuable tool to support and improve the decision making in a faculty. 
Table 2. The Potential Improvement of each Faculty

\begin{tabular}{|c|c|c|c|c|c|c|c|c|}
\hline \multirow{2}{*}{ Variable } & \multicolumn{2}{|c|}{ Faculty of Commerce } & \multicolumn{2}{|c|}{ Faculty of Law } & \multicolumn{2}{c|}{ Faculty of Education } & \multicolumn{2}{c|}{ Home Affairs } \\
\cline { 2 - 8 } & $\begin{array}{c}\text { CCR Min- } \\
\text { Input }\end{array}$ & $\begin{array}{c}\text { CCR Max- } \\
\text { Output }\end{array}$ & $\begin{array}{c}\text { CCR } \\
\text { Min- } \\
\text { Input }\end{array}$ & $\begin{array}{c}\text { CCR } \\
\text { Oux- }\end{array}$ & $\begin{array}{c}\text { CCR Min- } \\
\text { Input }\end{array}$ & $\begin{array}{c}\text { CCR Max- } \\
\text { Output }\end{array}$ & $\begin{array}{c}\text { CCR } \\
\text { Min- } \\
\text { Input }\end{array}$ & $\begin{array}{c}\text { CCR } \\
\text { Max- } \\
\text { Output }\end{array}$ \\
\hline $\begin{array}{c}\text {-Enrollment } \\
\text { Student }\end{array}$ & $-74.32 \%$ & $-40.87 \%$ & $-50.88 \%$ & $-23.48 \%$ & $-66.67 \%$ & $-62.29 \%$ & $-4.52 \%$ & $0.0 \%$ \\
\hline $\begin{array}{c}- \text { Student / } \\
\text { Teacher }\end{array}$ & $-56.58 \%$ & $0.0 \%$ & $-80.17 \%$ & $-69.11 \%$ & $-11.61 \%$ & $0.0 \%$ & $-56.5 \%$ & $-54.44 \%$ \\
\hline $\begin{array}{c}\text {-Master } \\
\text { Registration }\end{array}$ & $-56.58 \%$ & $0.0 \%$ & $-35.81 \%$ & $0.0 \%$ & $-11.61 \%$ & $0.0 \%$ & $-4.52 \%$ & $0.0 \%$ \\
\hline $\begin{array}{c}\text {-PhD } \\
\text { Registration }\end{array}$ & $-56.58 \%$ & $0.0 \%$ & $-35.81 \%$ & $0.0 \%$ & $-11.61 \%$ & $0.0 \%$ & $-4.52 \%$ & $0.0 \%$ \\
\hline $\begin{array}{c}\text { +Graduation } \\
\text { Number }\end{array}$ & $324.21 \%$ & $876.91 \%$ & $15.34 \%$ & $79.67 \%$ & $164.27 \%$ & $198.97 \%$ & $0.0 \%$ & $4.73 \%$ \\
\hline $\begin{array}{c}+ \text { +Master } \\
\text { Graduates }\end{array}$ & $754.41 \%$ & $1867.63 \%$ & $0 \%$ & $55.87 \%$ & $0.0 \%$ & $13.13 \%$ & $0.0 \%$ & $4.73 \%$ \\
\hline $\begin{array}{c}\text { +PhD } \\
\text { Graduates }\end{array}$ & $0.0 \%$ & $130.29 \%$ & $22.51 \%$ & $60.85 \%$ & $34.34 \%$ & $51.97 \%$ & $-4.52 \%$ & $95.99 \%$ \\
\hline $\begin{array}{c}\text { + \# of } \\
\text { Conferences }\end{array}$ & $0.0 \%$ & $130.29 \%$ & $27.55 \%$ & $98.7 \%$ & $80.51 \%$ & $104.21 \%$ & $87.14 \%$ & $79.37 \%$ \\
\hline
\end{tabular}

\section{References}

[1] Armstrong, J. Scott, (1985), " Long Range Forecasting" (New York: Wiley).

[2] B. Casu and E. Thanassoulis, "Evaluating cost efficiency in central administrative services in UK universities", Omega, 34(5) (2006) 417-426.

[3] Bel G. Raggad, "Neural network technology for knowledge resource management", Management Decision, 34 (2) (1996)20-24.

[4] Bijayananda Naik, Srinivsan Ragothaman , "Using neural networks to predict MBA student access" , College Student Journal (2004)

[5] Charnes, A., Cooper, W. and E. Rhodes, "Measuring the efficiency of Decision Making Units", European Journal of Operational Research, 26 (1978) 429-44.

[6] Coelli T, Prasada Rao DS, Battese GE. ,(1998), "An introduction to efficiency and productivity analysis. Boston/Dordrecht/ London: Kluwer Academic Publishers.

[7] Colbert, A., R.R. Levary, and M.C. Shaner, "Determining the relative efficiency of MBA programs using DEA", European Journal of operational Research, 125 (2000) 656-669.

[8] Cybenko, G. ,"Approximation by superpositions of a sigmoidal function.", Mathematical Control Signals Systems, 2 (1989) 303-314.

[9] Dennis Ahlburg, Michael McPherson, Morton Owen Schapiro, "Predicting Higher Education Enrollment in the United States: An Evaluation of Different Modeling Approaches ",(1994), http://www.williams.edu:/wpehe/DPs/DP-26.pdf

[10] Desheng(Dash) Wua, Zijiang Yang and Liang Liang, " Using DEA-neural network approach to evaluate branch efficiency of a large Canadian bank " , Expert Systems with Applications ,31(1) (2006) 108-115

[11] Dyson RG, Allen R, Camanho AS, Podinovski VV, Sarrico CS, Shale EA. ,"Pitfalls and protocols in DEA.", European Journal of Operational Research, 132 (2001)245-59.

[12] Elsa Cardoso, Maria Jose Trrigueiros , Patrciia Narciso, " A Balanced Scorecard Approach for Strategy - and Quality driven Universities", (2005) http://www.mc.manchester.ac.uk:80/eunis2005/medialibrary/papers/paper 174.pdf . 
[13] François Tavenas ,(2003), " Quality assurance : A Reference system for Indicators and evaluation Procedures " , European University Association, from web site: $\underline{w w w . e u a . b e}$

[14] Gabriel Tavares, "A Bibliography of Data Envelopment Analysis (1978-2001) ", (2002) RUTCOR RESERCH REPORT, http://rutcor.rutgers.edu/ rrr.

[15] G. Peter Zhang, Christine X. Jiang, " An Evaluation of Neural Networks for Exchange Rate Forecasting" , Paper submitted to The 28th Annual Meeting of the Decision Sciences Institute San Diego, California (1997), http:// clt.astate.edu / jseydel / dsi97 1.doc.

[16] Gilbert, E.W., Krishnaswamy , C.R. , Pashley , M.M, " Neural Network Application in Finance : A Practical Introduction " (2000)

[17] Hornik, K., Stinchcombe, M., \& White, H.," Multilayer feedforward networks are universal approximators.", Neural Networks, 2 (1989) 359-366.

[18] J. Colin Glass, Gillian McCallion, Donal G. McKillop, Syamarlah Rasaratnam and Karl S. Stringer, "Implications of variant efficiency measures for policy evaluations in UK higher education", Socio-Economic Planning Sciences, 40 (2) (2006)119-142.

[19] Jill Johnes , " Data envelopment analysis and its application to the measurement of efficiency in higher education" , Economics of Education Review, 25(3) (2006)273-288.

[20] Jill Johnes , (In Press), " Measuring teaching efficiency in higher education: An application of data envelopment analysis to economics graduates from UK Universities 1993 ", European Journal of Operational Research, In Press, Corrected Proof, Available online 17 May 2005.

[21] Marta Omero, Lorenzo D'Ambrosio, Raffaele Pesenti and Walter Ukovich, "Multiple-attribute decision support system based on fuzzy logic for performance assessment ", European Journal of Operational Research, 160(3) (2005) 710-725

[22] Nevena .S, V. Angelova, "Measuring the efficiency of university libraries using Data Envelopment Analysis", INFORUM: 10th conferences on professional Information Resources, Prague, May (2004) 25-27.

[23] Nunamaker, T.R., "Using data envelopment analysis to measure the efficiency of non profit organizations: a critical evaluation", Managerial and Decision Economics, 6 (1) (1985) 50-58.

[24] Othman Joumady and Catherine Ris.," Determining the relative efficiency of European Higher Education institutions using DEA ",http://www.egss.ulg.ac.be/economie/ris_appc.pdf

[25] Parag C. Pendharkar and James A., Rodger, "Technical efficiency-based selection of learning cases to improve forecasting accuracy of neural networks under monotonicity assumption" ,Decision Support Systems, 36(1) (2003) 117-136.

[26] Parag C. Pendharkar," Scale economies and production function estimation for object-oriented software component and source code documentation size", European Journal of Operational Research ,172(3) (2006)1040-1050

[27] Roger Hartley, Saud M.Y. Almuhaidib, "User oriented techniques to support interaction and decision making with large educational databases" , Computers \& Education, (2005).

[28] Smith, .J.N.D Gupta, "Neural Network in Business technique and applications for the operations researcher" , computers \& operations research , 27 (2000)1023-1044.

[29] Tsoukalas , 1.h ,and R.E.Uhrig, (1997), " Fuzzy and Neural Approaches in Engineering", New York :Wiley and sons.

[30] Turban .E, Aron son J.E , Loang .T.P, (2005),"Decision Support Systems and intelligent systems " , 7th ed. , Prentic Hall.

[31] White G.P. , " A survey of recent management science applications in higher education administration", Interfaces, 17(2) (1987) 97-108.

[32] Weiss, S.M. and Kulikowski, C.A.(1991), " Computer Systems that learn", San Mateo, CA: Morgan Kaufman Publishers, Inc.

[33] W.K. Wang, " Knowledge-based decision support system for measuring the performance of government real estate investment ", Expert Systems with Applications, 29(4) (2005) 901-912 .

[34] Wong B.K, Bodnovich Ta, and Selvi .Y., "Neural Network application in business: a review and analysis of the literature (1988-1995)", Decision Support System, 19 (1997) 301-32. 